\title{
OS MOVIMENTOS DE
}

\section{RFPATRIAMIFITO}

\author{
Marcia Anita Sprandel *
}

$\boldsymbol{I}$ este artigo, procuro chamar a atenção para um fenômeno recente no panorama das lutas sociais no campo: a reivindicação, pelo movimento social, do repatriamento de camponeses brasileiros que residem e trabalham em território de países limítrofes. ${ }^{1}$ Destaca-se o Movimento pelo Repatriamento dos Brasiguaios (MRB), criado em 1992, tendo como palavra de ordem "Brasil, uma Pátria para os Brasiguaios".'?

Os chamados brasiguaios surgiram, como grupo étnico e politico, nos primórdios da Nova República. Em julho de 1985 mais de mil famílias de pequenos produtores rurais brasileiros que haviam passado até mais de 20 anos residindo e trabalhando em terras localizadas na vizinha República do Paraguai, retornaram de forma organizada ao Brasil, alegando dificuldades econômicas e maus tratos em território paraguaio. A identidade brasiguaios, que funde em si os adjetivos pátrios do Brasil e do Paraguai, serviu como instrumento importante na luta pela reivindicação de terras, diante da possibilidade então concreta de realização de uma reforma agrária no Brasil.

Esteprimeiro contingente de retornados foi assentado no Projeto de Assentamento Novo Horizonte, em Ivinhema (MS), o qual, após seis anos, obteve sua emancipação política, tornando-se o município de Novo Horizonte do Sul. ${ }^{3}$ Depois destas, outras familias retornaram de forma organizada ao Brasil. A cada experiência com menos êxito, devido aos desdobramentos conhecidos da política fundiária no país.

Em maio de 1992, um novo grupo de brasiguaios, formado por 400 famílias, ergueu um acampamento em Amambai

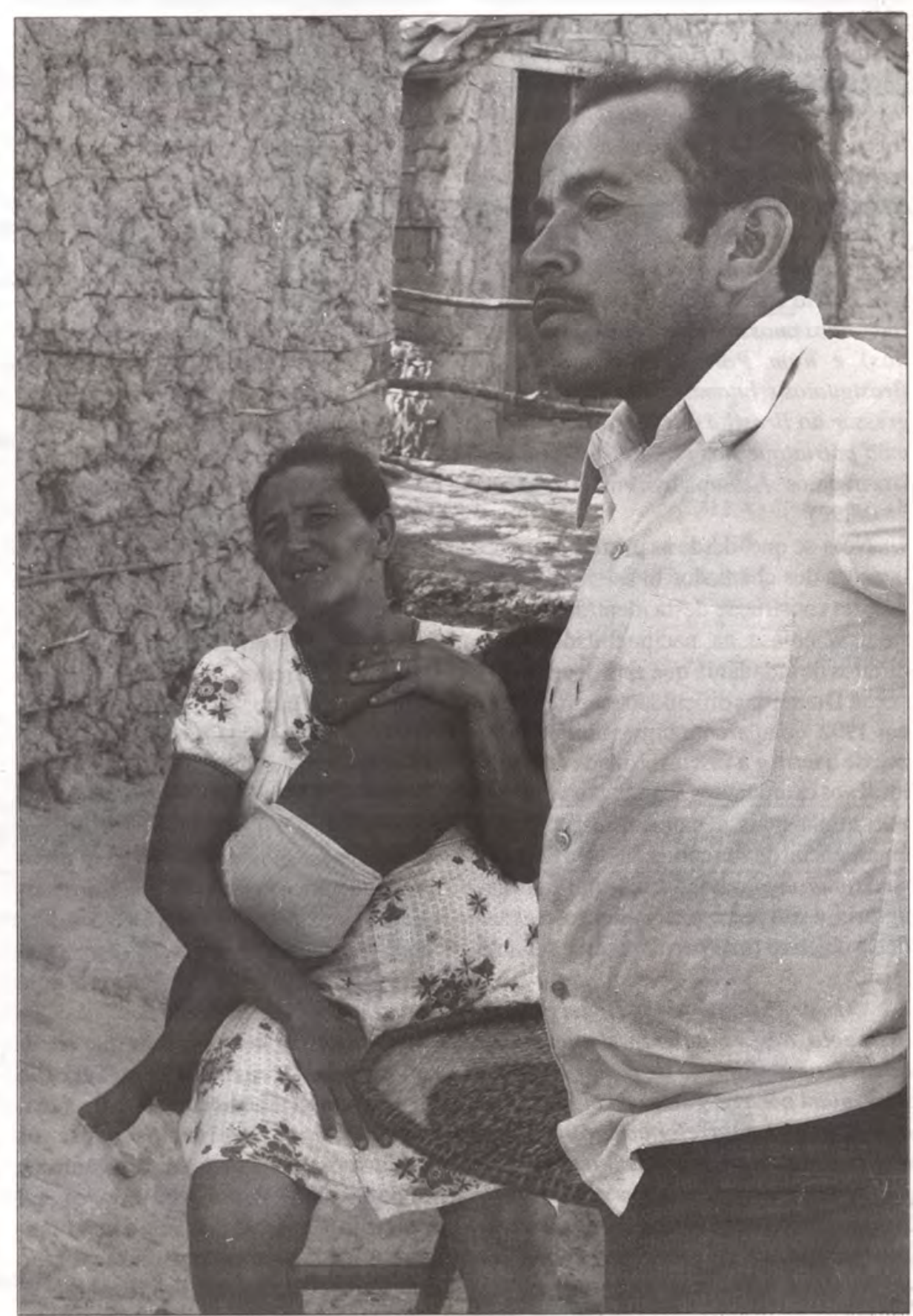

Foto: Arquivo CEM 
(MS). Ali sofreram pressões para retornar ao Paraguai e foram vítimas de atos de violência (prisões, invasões de acampamento, espancamentos) por parte do governo estadual. ${ }^{4}$ Em carta que os acampados divulgaram à opinião pública, apareceu, pela primeira vez na história daquele grupo social e mesmo na história das lutas camponesas no Brasil, a sugestão de que seriam refugiados aqueles camponeses tradicionalmente percebidos como " "migrantes" ou como parte constitutiva de processos de formação de novas fronteiras agrícolas. No mesmo documento, os chamados brasiguaios reivindicaram ao governo federal seu repatriamento:

" O Brasil já nos rejeitou há mais de três décadas, quando nos arrancou da terra e nos obrigou a buscar refúgio no Paraguai. Hoje o Paraguai, da mesma forma, não nos dá condições de sobrevivência e uma cidadania digna. Estamos sem Pátria e sem terra. Nem Brasileiros (poisnãotemosnossos direitos reconhecidos) e nem Paraguaios. Somos os Brasiguaios e lutamos pelo direito de regressar ao Brasil e dar aos nossos filhos uma pátria que nos receba. " (Carta dos Brasiguaios Acampados em Amambai, 25.05.92)

Nota-se que, desde as primeiras mobilizações dos chamados brasiguaios, e na própria construção desta identidade, houve uma ênfase na nacionalidade e nos direitos de cidadania que esta deveria fornecer. Diante das dificuldades enfrentadas em 1992 - a aparente impossibilidade de acesso a terra e a insensibilidade do poder local - os camponeses acampados ressaltaram ainda mais a natureza específica e emergencial de sua condição. Não se tratava de mais uma reivindicação por reforma agrária, e sim por repatriamento, mesmo que o objetivo final permanecesse sendo a terra:

'O problema dos Brasiguaios extrapola, nesse momento, a questão da terra. É uma situação de repatriamento. Eles lutam para resgatar sua cidadania e essa luta passa pela reforma agrária. É um contingente de cidadãos sem terra e sem pátria e que deveriam ser acolhidos pelo Estado como individuos que regressam a sua terra na busca de melhores condições de vida que não conseguiram ter no es- trangeiro. E, no entanto, são recebidos à bala, humilhados, marginalizados e segregados em campamentos. $O$ repatriamento é um direito universal garantido pela Constituição Brasileira e está contido na Declaração dos Direitos Universais do Homem, assinada pela ONU, da qual o Brasil é signatário". (ibid.)

O MRB foi criado no Estado do Mato Grosso do Sul, escolhido como ponto de chegada para os brasiguaios que retornam mobilizados pela facilidade da fronteira seca e pelo trabalho de mediação ali realizado. Seus membros apoiam política e estrategicamente os grupos de camponeses que desejam retornar ao Brasil e aqueles já acampados, e divulgam suas reivindicações. O movimento é formado por sindicatos, entidades, organizações e partidos políticos sul-matogrossenses. ${ }^{5}$

A articulação política do MRB é feita pelo Comitê Binacional dos Brasiguaios, criado em 1991, do qual fazem parte entidades sindicais, partidos políticos e ONGs do Brasil e do Paraguai, envolvidos diretamente na defesa dos interesses dos chamados brasiguaios e no apoio a sua organização e às mobilizações de retorno ao Brasil. Atualmente tem como representantes brasileiros o Movimento dos Trabalhadores Rurais Sem Terra, a Central Única dos Trabalhadores, a Secretaria Agrária do Partido dos Trabalhadores e o Centro de Defesa dos Direitos Humanos Marçal de Souza. Do lado paraguaio temos a Federación Nacional Campesina (FNC), a Coordinadora Interdepartamental de Sin Tierras (CIST), a Organización de Lucha por la Tierra (OLT), o Comité Popular por los Derechos Humanos (CPDH) e o Partido Democrático Popular (PDP). Em determinadas situações, há uma fusão das duas representações, e documentos são assinados pelo "Comitê Binacional pelo Repatriamento dos Brasiguaios'.

Além de publicar encartes que circulam junto ao Jornal dos Sem Terra, o MRB reúne-se anualmente durante a realização dos "'Seminários sobre os Brasiguaios', cuja sexta edição aconteceu em junho de 1994, em Assunção, capital paraguaia. Cabe ressaltar aqui a importância e o ineditismo do trabalho realizado pelo Comitê Binacional dos Brasiguaios, que tem se firmado como força política respeitada no Brasil e no Paraguai, como mediador preferencial em situações de conflitos (sejam estes trabalhistas, de terra ou étnicos) na fronteira internacional. $\mathrm{O}$ conhecimento localizado que seus integrantes possuem lhes permite inclusive sugerir políticas públicas para a região, como veremos adiante.

Uma outra proposta de repatriamento, geograficamente diversa, com outro nivel de mobilização e de complexidade, apareceu em julho de 1994, quando o Conselho Nacional dos Seringueiros anunciou sua intenção de lutar pelo repatriamento de 15 mil brasileiros - denominados localmente "brasivianos" - que estariam trabalhando em seringais bolivianos. O levantamento da situação destes brasileiros foi feito em 1991 pela Diocese de Rio Branco e pelo Vicariato de Pando $^{6}$, e em 1992 por uma Comissão de Deputados da Assembléia Legislativa do Acre. As representações sobre os motivos de saída do Brasil e as dificuldades enfrentadas na Bolivia lembram os relatos de história de vida feitos pelos chamados brasiguaios:

"Para ter um rebanho bovino estimado em mais de um milhão de cabeças, o Acre pagou um alto preço ambiental: entre as décadas de 60 e 70, desmatou milhares de hectares de florestas, destruiu seringais inteiros e obrigou cerca de 15 mil brasileiros a migraremà cidadede Pando, na Amazônia boliviana. (...) Na Bolivia, os brasileiros são obrigados a pagar renda mensal aos donos da terra onde trabalham e vivem irregularmente no pais. Comissão de deputados da Assembléia Legislativa do Acre constatou, em novembro de 1992, que muitos brasileiros eram humilhados e alguns torturados por policiais bolivianos, por não conseguirem pagar as taxas escorchantes exigidas pelos proprietários '. (Jornal do Brasil, 06 de julho de 1994).

O Conselho Nacional dos Seringueiros (CNS) estaria contando com o apoio do Banco Mundial para organizar o repatriamento, que seria uma das metas do programa da entidade de representação para a proteção das florestas na Amazônia. Conforme a notícia, os seringueiros provenientes da Bolivia seriam incorporados ao plano de expansão produtiva da reserva 
extrativista Chico Mendes. Em contato telefônico feito em agosto de 1994, um dirigente do Conselho esclareceu, no entanto, que a proposta de repatriamento não objetiva assentar seringueiros na RESEX Chico Mendes, tratando-se de uma reivindicação mais ampla.

Da mesma forma que os chamados brasiguaios desde 1985 têm voz e voto nos congressos do Movimento Sem Terra, também os chamados "brasivianos" têm tido voz e voto nos congressos do CNS. O fato do individuo estar além de uma fronteira física não significa, pois, que não esteja participando do movimento social em seu pais de origem, ou alijado de seus direitos políticos, como o de votar. O que está em jogo, não é a emigração para outro país, mas sim a busca de novas terras ou, no caso dos seringueiros, novas colocações.

Os camponeses brasileiros no Paraguai ou os seringueiros brasileiros na Bolívia não poderiam ser considerados, desta maneira, "refugiados" no significado clássico do termo. Ofato de "buscarem refúgio" nestes países limítrofes também não se refere à idéia biológica de "refúgio" " como habitat. Trata-se, antes, da idéia de "refúgio" conforme percebida pelo senso comum, como abrigo, segurança circunstancial a um momento de crise. "Repatriamento", quando aparece nas suas reivindicações, é fundamentalmente uma bandeira de luta emprestada ao discurso do direito e das agências internacionais.

Veremos, a seguir, o que significa formalmente repatriamento, e porque tem sido reivindicado naquelas situações de conflito social envolvendo cidadãos brasileiros que circulam pelas fronteiras de países limítrofes. Como funciona esta categoria em tais situações sociais, sendo ou não percebida por aquela sua irmã, refugiados?

\section{O Repatriamento na Literatura Diplomática e no Direito Internacional}

Ascategorias repatriamento e refugiado estão intimamente ligadas aos conflitos armados da primeira metade do século $\mathrm{XX}$, e foram construídas e conceituadas através de atos jurídicos. Repatriamento é, segundo o Encyclopaedic Dictionary of International Law (1988), o termo empregado nas leis de guerra para referirse ao retorno de pessoas para seu país de origem. ${ }^{7}$ Refugiados, conforme a mesma fonte, seriam pessoas assim consideradas pelas diversas legislações ${ }^{8}$, por possuirem medo bem-fundado de perseguição por razões de raça, religião, naturalidade, pertencimento a um determinado grupo social ou opinião política, eque estivessem fora de seu país de nacionalidade.

Em outubro de 1921, finda a Primeira Guerra Mundial, os países vencedores, organizados através da Liga das Nações ${ }^{9}$, criaram a League of Nations High Comissioner for Refugees, a cargo de Fridtjof Nansen. O órgão teve como principal tarefa apoiar - através de emissão de documentos e procura de empregos - refugiados da revolução soviética de 1917 e do conflito grego-turco de 1922. Em 1933 aconteceu o êxodo de refugiados da Alemanha, obrigando a Liga das Nações a estabelecer um escritório para o Alto Comissariado. Em 1938, por iniciativa do presidente Roosevelt (USA), foi criado o Intergovernmental Committe for Refugees (IGCR). Funcionou até 1947, tendo como preocupação as centenas de milhares de refugiados da Segunda Guerra Mundial.

Em dezembro de 1944, surgiu a United Nations Relief and Rehabilitation Administration (UNRRA), que tinha um propósito essencialmente prático: planejar, coordenar e administrar medidas de apoio às vítimas da guerra em qualquer área sob controle das Nações Unidas, através do fornecimento de comida, roupas, abrigo e outras necessidades básicas. Diferentemente das organizações anteriores, seu trabalho foi todo realizado em campo, ajudando os governos aliados a repatriar mais de 6 milhões de pessoas.

Com o final da guerra, o problema dos refugiados permaneceu, entre outros motivos, porque mais de um milhão deles não quisera ser repatriado. Havia a necessidade de se criar uma organização que centralizasse as tarefas do antigo Alto Comissariado da Liga das Nações, do IGCR e da UNRRA. Surgiu a International Refugee Organization (IRO), que funcionou de 1947 a 1951 . Destaca-se na leitura de seu termo de referência a preocupação em definir o status de refugiado, significativamente por exclusão. A IRO tinha um interesse constitucionalmente limitado a determinados grupos e categorias de refugiados, que deveriam satisfazer certas condições antes de utilizar-se de seus serviços.

Em $1^{\circ}$ de janeiro de 1951 , começou a funcionar em Genebra o escritório do Alto Comissariado das Nações Unidas para Refugiados (ACNUR), ou Office of the United Nations High Commissioner for Refugees (UNHGR). Sua tarefa era a de dar proteção a todos os refugiados então reconhecidos oficialmente $(125 \mathrm{mil})$ e a qualquer outra pessoa que deixasse seu país por medo de perseguição ou que não desejasse retornar, pelo mesmo motivo. Foi elaborada uma Convenção em 28 de julho de 1951 , cuja adesão por 24 países significou a possibilidade de fornecimento de um status legal para os refugiados. ${ }^{10}$ Este instrumento, originalmente limitado a pessoas que tinham se tornado refugiadas como resultado dos acontecimentos anteriores a $1^{\circ}$ de janeiro de 1951 , foi ampliado através de Protocolo de 1967, que tornou suas ações aplicáveis às novas situações, a despeito de qualquer data limite" .

Pode-se dizer que, a partir de 1967 , como parte deum processo de reformulação das políticas do ACNUR, a categoria refugiados deixa de estar exclusivamente ligada a conflitos armados. Para GORDENKER (1987) haveria um problema de insuficiências definitórias tanto na Convenção quanto no Protocolo. A definição de "refugiados" na Convenção de 1955 determina a perseguição deliberada por parte de um governo como motivo para se adquirir este status. Para o autor, a especificidade deste argumento excluiria os efeitos das ações governamentais que ameaçam a existência de indivíduos e grupos sem tomar a forma de punições ou ameaças explícitas. A definição, desta forma, não incluiria muitos dos resultados de políticas sociais que estariam envolvidos em grandes êxodos ou migraç̃es forçadas.

Se, em 1951, o ACNUR estava preocupado em dar proteção a indivíduos e grupos de famílias que haviam se tornado refugiados como resultado da Segunda Guerra Mundial, a maior parte europeus, hoje precisa pensar também em comunida- 
des inteiras, e mesmo grupos étnicos e tribais (a maioria parte do chamado "Terceiro Mundo"') ${ }^{12}$, um universo de mais de 22 milhões de refugiados por motivos econômicos e políticos. Há uma reavaliação na própria função contemporânea do Alto Comissariado, qual seja: fornecer " proteção internacional" a refugiados e propor soluções permanentes aos seus problemas. Conforme o próprio órgão, a " proteção internacional deve ser pensada como algo dinâmico, e não como um conceito estático, aplicado rigorosamente"' (UNHCR; 1971:42).

O ACNUR funcionaria, atualmente, como mediador entre os refugiados e o governolocal, ou, no caso de repatriamento, entre o país de asilo e o país de origem. Assim que recebe um apelo por ajuda, um representante do Alto Comissariado é indicado para avaliar a situação, discutindoa com autoridades locais e agências voluntárias, ou outras organizações envolvidas. Sendo concedido pelo país de primeiro asilo o status de refugiados para um indivíduo ou grupo de pessoas, o ACNUR apresenta três possibilidades de solução para o problema: o repatriamento, o reassentamento no país de primeiro asilo ou o reassentamento em um terceiro país.

No caso dos chamados brasiguaios, ou dos seringueiros na Bolívia, não houve formalmente a requisição do status de refugiados ao ACNUR. Avançaram diretamente para a reivindicação de repatriamento, a qual não passa ainda pelas agências internacionais, sendo dirigida aos aparatos de estado do Brasil. Trata-se de uma apropriação, por parte dos camponeses envolvidos em tais situações sociais, de uma categoria e de um discurso ao qual ascenderam através de negociações políticas com representantes da diplomaciabrasileira, encarregados oficialmente de seu conforto em país estrangeiro. $\mathrm{O}$ departamento consular do Itamaraty vem se destacando como nova e fundamental agência na cadeia de interlocução que os mediadores do movimento social precisam percorrer na busca de resolução para os conflitos envolvendo cidadãos brasileiros, em sua grande parte camponeses, que vivem em territórios de países limítrofes.

Quando do surgimento do primeiro acampamento dos chamados brasiguaios, em 1985, o fórum escolhido para a resolução do problema foi o Grupo de Cooperação Consular Brasil-Paraguai. Dele fazem parte diplomatas e funcionários de órgãos estatísticos, policiais e fundiários dos dois países. Na Segunda Reunião, realizada em Brasília (DF) em outubro daquele ano, constatou-se a inexistência de dados confiáveis sobre o número de brasileiros residentes no Paraguai e chegou-se à conclusão que a raiz do problema seria a documentação pessoal dos imigrantes. Destacou-se a necessidade de garantir a propriedade da terra e de assegurar os direitos daqueles arrendatários ou parceiros, tanto em imóveis de paraguaios como de brasileiros. As repartições consulares brasileiras no Paraguai foram autorizadas a manter livros para registro de títulos de propriedade de terra e de contratos de arrendamento ou parceria dos camponeses brasileiros, o que lhes permitiria defender os direitos dos mesmos diante das autoridades paraguaias.

Em meados de 1986, realizou-se em Assunção, capital paraguaia, a Terceira Reunião do Grupo de Cooperação Consular Brasil-Paraguai. $\mathrm{Na}$ agenda de trabalho, estavam o exame dos requisitos legais vigentes para registro dos nacionais de cada país no território do outro; censo de cidadãos brasileiros residentes em áreas rurais no Paraguaie de cidadãos paraguaios residentes no Brasil; formação de recursos humanos na área aduaneira e na área policial e a instalação de comitês de fronteira em Guaíra (PR) - Salto del Guairá (PY) e em Ponta Porã (MS) e Pedro Juan Caballero (PY).

Apesar dos representantes dos chamados brasiguaios não terem assento nas reuniões, abriu-se um canal de comunicação através do envio de cartas, denúncias e solicitação de audiências e reuniões com funcionários do Itamaraty. Foi o início de uma interlocução nova tanto para a diplomacia como para o movimento social. No caso da primeira, naqueles países onde os cidadãos brasileiros que devem proteger são em sua maior parte camponeses que vivem em área limítrofes à fronteira com o Brasil, criou-se a necessidade de deslocamento de funcionários dos escritórios consulares urbanos e burocráticos para áreas de conflito. Quanto ao segundo, o aprendi- zado de uma mediação política que passa necessariamente pelos departamentos consulares. Tal aprendizado foi lento e pressupôs a consciência, por parte dos chamados brasiguaios e seus representantes, de sua condição de estrangeiros em um país vizinho.

Depois de diversas tensões e tentativas frustradas de aproximação, aconteceu, em fevereiro de 1993, em Ciudad del Este (PY), uma reunião histórica entre representantes consulares brasileiros, entidades sindicais, políticas e de apoio aos chamados brasiguaios (as mesmas que conformam o MRB), além de membros das comunidades locais. Da reunião resultou um decálogo de propostas objetivas, enviadoà chancelaria brasileira. Além do repatriamento, estas propostas referem-se ao bem estar e à resolução de conflitos envolvendo brasileiros que permanecem em território paraguaio. Um ano e meio depois, durante a realização do VI Seminário sobre os Brasiguaios, em Assunção (PY), o Cônsul Geral da República Federativa do Brasil naquele pais relatou quais as propostas que foram factíveis de execução, e quais seus resultados.

O primeiro item refere-se a um esforço para regularizar a situação documental de componeses brasileiros no Paraguai, como primeiro passo para um plano de ajuda que incluiria assistência médica e educacional. O segundo, previa a implementação com a máxima urgência, de um sistema de visitas consulares itinerantes, tendo sido indicadas duas colônias prioritárias: Bernardino Caballero e Nueva Esperanza, no distrito de Ybiahú, Departamento Concepción. $\mathrm{O}$ argumento da escolha, por parte do consulado, exatamente o oposto ao argumento do movimento social, foi a facilidade de acesso e a não possibilidade de conflito.

Foram realizadas três missões consulares itinerantes, nas quais funcionários da Secretaria de Estado e do consulado brasileiro se deslocaram para as áreas escolhidas. Houve distribuição de cartilhas consulares e o esclarecimento de que ali estavam para ouvir e orientar os cidadãos brasileiros. Funcionários do consulado cadastraram os brasileiros e registraram os nascimentos. Apenas num dia, em Nueva Esperanza, foram cadastrados 201 brasi- 
leiros e registradas 8 crianças. Também em um dia, em Bernardino Caballero, foram cadastrados 191 brasileiros e registradas 52 crianças. No relato da chefe desta missão, há a categorização desta nova modalidade de atendimento consular como "uma verdadeira aventura, nada burocrática, mas gratificante sob todos os aspectos"' (PUGLIA; 1993:1).

As cartilhas consulares distribuidas em Concepción foram uma reivindicação do movimento social na reunião de Ciudad del Este, qual seja: "elaboração de uma cartilha consular em linguagem didática com informações sobre documentação e direitos assegurados aos colonos brasileiros'". Há dois tipos de cartilha, a Cartilha Consular Brasileira - informações básicas para cidadãos brasileiros residentes no Paraguai e Informações Básicas para Cidadãos Brasileiros Residentes no Paraguai a Respeito da Concessão de Documentação Paraguaia para a Permanência Legal no País.

O trabalho de missões itinerantes realizado pelo consuladobrasileiro no Paraguai está sendo considerado um modelo para situações congêneres, como o acompanhamento de brasileiros nos EUA, durante a realização da Copa do Mundo e poderá ser adotado pela chancelaria paraguaia na orientação aos milhares de cidadãos paraguaios que vivem na Argentina. Configura-secomo uma vitória para a diplomacia brasileira $\mathrm{e}$ paraa sociedade civil organizada, resultante de um exercício muitas vezes tenso, porém insistente, de interlocução.

Não obstante seu alcance geograficamente e socialmente reduzido, as missões consulares itinerantes marcam uma nova fase no papel da diplomacia em conflitos sociais em regiões de fronteiras políticoadministrativas internacionais. O Cônsul Geral do Brasil em Assunção, Sr. Luis Brun de Almeida e Souza, chama esta nova fase de "Diplomacia Consular Social", uma percepção diversa das responsabilidades consulares, que em parte teria nascido do problema doschamados brasiguaios. Brun destacou, em relato feito no VI Seminário, a importância da presença consular nas áreas de campo, levando em conta além dos casos de corrupção de autoridades locais, outras situações sociais que caracterizam esta região de fronteira (con- trabando, narcotráfico, roubo de carros):

"'É impressionante a diferença que é estar lá e não estar lá. Estas unidades móveis consulares que chegam causam uma grande transformação na área de atendimento. A melhor maneira de combater uma situação de corrupção ou um esquema clandestino, nestas áreas $\dot{e}$ a presença! Porque as pessoas que trabaIham ilicitamente ofazem aproveitando a ausência de autoridade governamental". (Conferência realizada em 23 de junho de 1994, durante a realização do VI Seminário sobre os Brasiguaios, em Assunção, Paraguai).

O Cônsul destacou, ainda, a necessidade de treinamento de funcionários para estas novas atividades consulares e 0 atendimento de uma outra reivindicação do "decálogo", a extensão da assistência jurídica aos brasileiros no interior do Paraguai. O consulado contratou um consultório de advocacia em Assunção para prestar assistência jurídica em casos de conflitos de terra, conflitos com cidadãos paraguaios, e demais situações que envolvam autoridades daquele país. O repatriamento, demanda do movimento social, não foi discutido pela autoridade diplomática naquela reunião.

A participação das chancelarias brasileira e paraguaia no VI Seminário demonstra, outrossim, uma aproximação maior entre a diplomacia e o movimento social nas regiões de fronteiras internacionais. Quando se dá o retorno organizado ao Brasil, e os camponeses se encontram face a face com autoridades locais brasileiras pouco propensas a atender suas demandas por terra, éà diplomacia que mais uma vez vão recorrer, utilizando-se de categorias que lhes são próprias, como aquela de repatriamento. Resgatam sua condição de "refugiados econômicos" e realizam uma forma diferente e organizada de "migração de retorno".

\section{As Fronteiras internacionais no contexto da globalização}

No processo de organização das mobilizações camponesas e dos planejamen- tos públicos nas fronteiras internacionais brasileiras verifica-se um deslocamento constante da percepção de "fronteira" em jogo. Quando os camponeses entram em território paraguaio ou boliviano em busca de terras ou colocações, a fronteira político-administrativa internacional é relativizada. Quando surgem as mobilizações pelo retorno, esta passa a ter um papel fundamental na construção de identidades étnicas e nas estratégias de luta.

De parte dos aparatos de poder, também percebe-se uma dualidade. De um lado, geopolíticos nacionalistas atribuem historicamente às regiões fronteiriças um caráter ofensivo e defensivo, considerando-as espaços periféricos a serem resguardados (vide Projeto Calha Norte). Por outro lado, governantes e funcionários das novas agências que estão envolvidas, entre outras questões, na implantação do Mercado Comum do Sul, apostam na relativização destas fronteiras, através do conceito de "regionalidade".

A idéia de regionalidade aparece no Projeto de Protocolo Regional firmado em 11 de agosto de 1987 entre seis províncias argentinas (Entre Rios, Corrientes, Misiones, Santa Fé, Chaco e Formosa) e os estados brasileiros de Rio Grande do Sul, Paraná e Santa Catarina:

" Se considera (a fronteira) como uma área ou sub-região na qual se entrecruzam diversas forças que convergem no lugar (políticas, econômicas, sociais) e geram um sistema dinâmico. De tal maneira, a ocupação e organização do espaço se deve transformar numa identidade, na qual sem perder seus perfis próprios, ambas nações se somam na luta pela concretização de objetivos comuns. (...) A (sub)região é o espaço no qual se vinculam ou inter-atuam duas populações. Este contato se reflete no espaço e dá identidade própria a (sub)região. Daqui se extraem duas consequências importantes: a (sub)região fronteiriça excede o limite político e se extende a uma franja que inclui a ambos os países; a (sub)região fronteiriça não seria dividida por limites políticos, mas sim permite o seu tratamento como um todo". (RECONDO; 1988:42-43)

Como concretização desta subregionalidade, são apontados os chamados Comitês de Fronteira, "organis- 
mos oficiais integrados por representantes do setor público que tendem a promover a cooperação e o desenvolvimento regional nas subregiões ou áreas de fronteira e a proporcionar soluções ágeis e pragmáticas aos problemas de tráfego fronteiriço" (RECONDO; ibid:35). Além da regularização operativa do tráfego de pessoas, veículos e mercadorias, previam na sua

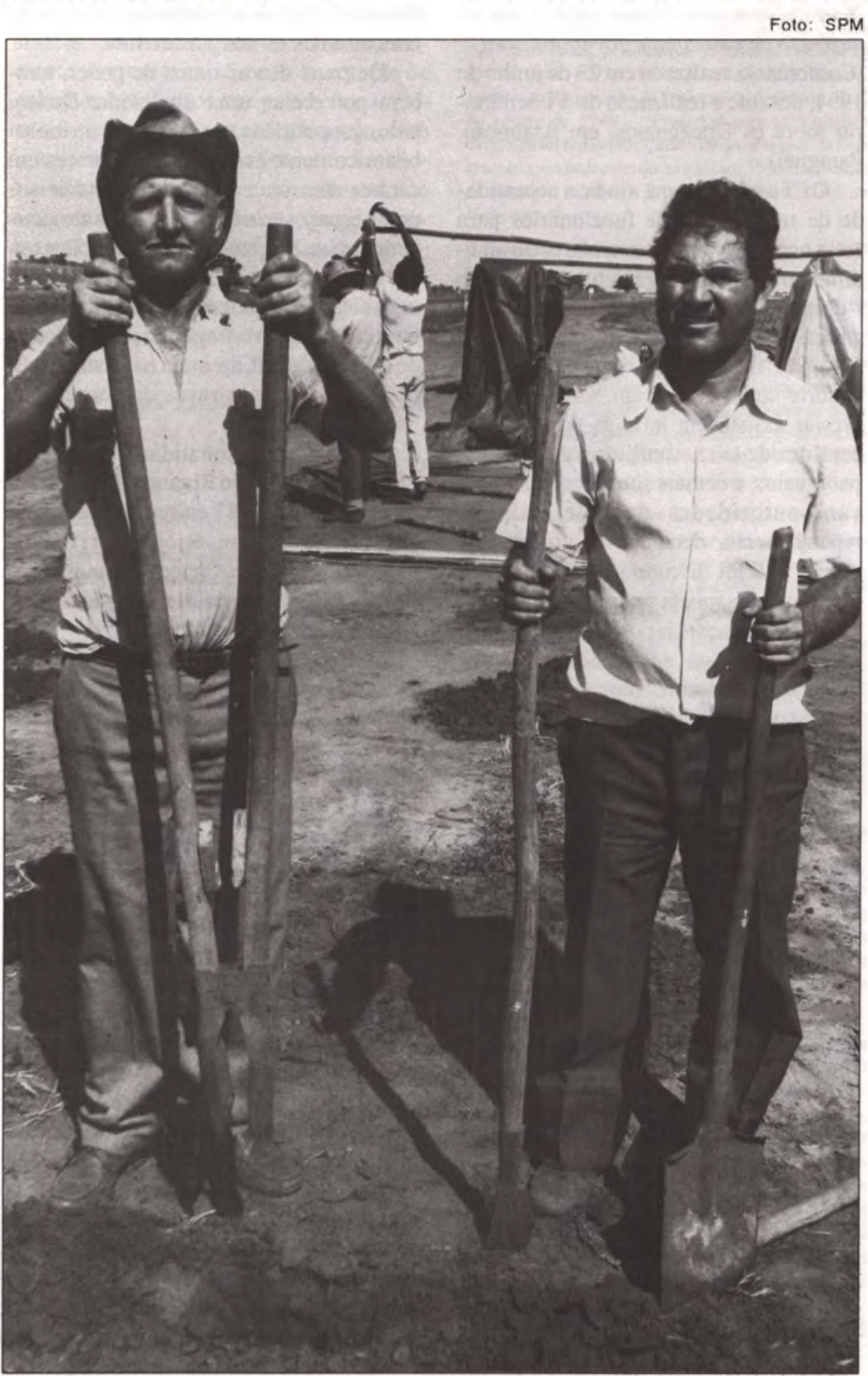

criação a instalação de um fórum para o tratamento de problemas e conflitos fronteiriços.

Em fevereiro de 1995, os governadores argentinos de Entre Rios, Corrientes, Misiones e Chaco, e os governadores brasileiros de Paraná e Santa Catarina (os governadores de Formosa e do Rio Grande do Sul não compareceram, mas deverão

to: SPM 
dos cortadores de cana brasileiros que disputam o mercado com os uruguaios em Bella Unión, sendo usados para baixar o preço do corte.

Para BRIGHT \& GEYER (apud MARCUS 1991), e todos que se preocupam com os novos rumos da história mundial, é necessário deter-se na análise da interação entre as forças que promovem a integração global e as forças que recriam uma autonomia local. Estas últimas, onde seenquadram os grupos sociais que estamos analisando, tendem a ser vistas pela visão "'moderna" como retrógradas ou reacionárias. Para os autores, elastêm uma importância fundamental exatamente por estarem estabelecendo os termos de uma participação autocontrolada e autodeterminada nos processos de integração global e na luta por uma ordem planetária.

Considero de Stuart Hall (1993) a mais clara reflexão sobre estas contradições, ao questionar a noção de globalização como um espaço não contraditório e incontestável. As novas formas de globalização e homogeneização, concentradoras de capital, afirma o autor, só governam através de capitais locais, junto com elites políticas e econômicas locais, assimilando as particularidades e especificidades do local, inclusive as diferenças de gênero. Ao se implantarem estas novas formas de globalização - como o Mercosul - dá-se a emergência de novos sujeitos, novos gêneros, novas etnicidades, novas regiões, novas comunidades. Através da luta, estas adquirem os meios de falar por si mesmas, ameaçando o discurso do poder. A etnicidade - seja ela de brasiguaios, "brasivianos" ou "refugiados" - seria o local necessário de onde as pessoas podem falar neste final de século marcado pela implantação de macro-mercados.

É nesta perspectiva que se pode recuperar o significado contemporâneo da categoria "refugiados". Não obstante tratarse de uma categoria datada, seu sufixo tornou-se rotativo, significando sempre excluídos de alguma coisa e afastamento compulsório. Existem referências a "refugiados do desenvolvimento", conforme Mimi Kleiner, do Enviromental Found, ao referir-se às pessoas deslocadas pelas obras do progresso, tais como barragens, portos eáreas reservadas militares. Na Conferência das Nações Unidas sobre. Mudanças
Climáticas, que aconteceu em Berlim em março de 1995, especialistas do Instituto do Clima, de Washington, afirmaram que a deteriorização do meio ambiente criou pelo menos 25 milhões de refugiados no mundo inteiro, obrigados a emigrar por fatores predominantemente ambientais. Seriamos "refugiados ecológicos". Como excluidos de um processo global, os "refugiados" são ao mesmo tempo parte e ameaça.

Os movimentos de repatriamento de grupos sociais cobertos por categorias étnicas, como os chamados brasiguaios, seringueiros, ou ainda, brasivianos, precisam ser analisados tendo como pano de fundo estas novas formas de globalização, inclusive suas propostas de administração das questões fronteiriças. O retorno de camponeses de áreas de países limítrofes para seus locais de origem, de forma desorganizada e individual, permanece acontecendo. Mas as peculiaridades da nova situação internacional, com aumento do espaço de negociação política com agentes transnacionais, novas propostas de organização sindical também transnacionais, e o aumento do controle de migrações nas fronteiras nacionais, exigem, permitem e condicionam a emergência de novas formas de migração de retorno, na qual os sujeitos não se consideram mais meros "'migrantes"' em um eterno processo de deslocamento movido por motivos econômicos e sociais.

Sabe-se que grande parte dos refugiados, dos sem-pátria do mundo contemporâneo, começaram por ser sem-terra. A reforma agrária nos paises de origem seria a solução para os problemas de milhares de camponeses brasileiros, bolivianos, paraguaios e chilenos que circulam pelas fronteiras do Cone Sul em busca de terra e trabalho. A implantação do Mercosul significou um novo desafio para os trabalhadores sul-americanos, na medida em que implementou o diálogo entre as diversas centrais sindicais e entre estas e novos aparelhos de poder. Em nivel local, os conflitos inter-étnicos são negociados por organizações camponesas dos paises envolvidos (como no caso da atuação do Movimento dos Trabalhadores Rurais Sem Terraeda Federación Nacional Campesina nos conflitos entre camponeses brasileiros e paraguaios). Neste quadro complexo, entidades como o Movimento pelo Repatriamento dos Brasiguaios e o Comitê Binacional dos Brasiguaios destacam-se como agentes sociais imprescindiveis.

A diplomacia também enfrenta seus desafios, ao tornar-se parte atuante em um diálogo com colegas dos outros países signatários do Mercosul, com empresários, centrais sindicais e parlamentares, entre outros grupos sociais que estão sendo afetados pela integração dos mercados. Em entrevista concedida durante a realização da Cúpula das Américas, em dezembro de 1994, Fernando Henrique Cardoso declarou que o Itamaraty, tradicionalmente voltado para si mesmo," "tem um pouco de receio de seabrir, um pouco da visão antiga de que os assuntos dele são assuntos de Estado. Hoje, não se tem mais assuntos de Estado, todos os assuntos são da nação, da sociedade"' (Folha de São Paulo, 18/12/ 94).

Roberto da Matta, em recente artigo, fez a defesa da sensibilidade de alguns diplomatas para problemas culturais, no que se aproximariam do trabalho dos antropólogos:

“(...) As viagens, que são a marca registrada da diplomacia e da antropologia, promovem uma leitura mais generosa do mundo. Pois elas revelam que o conhecimento não é somente uma concepção que permite realizar alguma coisa prática - um juntar de armas ou dinheiro; mas é acima de tudo, uma experiência humana.(...) Diferentemente das viagens turisticas que confirmam todas as superioridades, trata-se de uma viagem (...) na qual quem se deseja em causa é o próprio viajante. Viajante que abre mão de ser único foco de entendimento e o fiel exclusivo da balança do que viu, que aprendeu e viveu. " (DA MATTA; 1993:1-2)

Políticos, religiosos, sindicalistas, camponeses, e mesmo antropólogos, fazem parte de um campo político e de conhecimento que se localiza na articulação entre o global e o local. No caso das fronteiras internacionais brasileiras, dele também fazem parte latifundiários, narco-traficantes e contrabandistas, que controlam os deslocamentos fronteiriços e têm grande força nas eleições regionais. A diplomacia aponta como novo e fundamental agente não somente pela qualidade de sua presença entre as populações fronteiriças, mas 
também por sua ação mediadora nos conflitos sociais que lhes atingem.

Numa conjuntura internacional de relativização das fronteiras e de esvaziamento do papel dos estados-nacionais, em que a noção de Pátria parece estar perdendo muito de seu valor, seria mínima a possibilidade de vitória para grupos sociais que têm como bandeira de luta justamente a nacionalidade. Funcionários consulares, na medida em que tradicionalmente tiveram como função a proteção de cidadãos brasileiros em países estrangeiros, estão se transformando $\mathrm{em}$ interlocutores privilegiados junto aos movimentos de repatriamento e diante das demandas de brasileiros que desejam permanecer residindo e trabalhando em paises limítrofes. Desta relação poderá resultar a garantia aos direitos fundamentais de cidadania, entre eles o de retornar ao país de origem.

\section{- Marcia Anita Sprandel é historiadora e antropóloga.}

\section{NOTAS}

1. Atualmente, a autora está ligada ao projeto "Trabalho, integração e conflito entre grupos étnicos, nacionais e estrangeiros, no nordeste argentino", desenvolvido no Museu Nacional/UFRJ através de convênio com a Universidade de Buenos Aires, e financiado pela Fundaçâo Vitae. "Vitae não compartilha, necessariamente, dos conceitos e opiniōes expressos neste trabatho, que é de exclusiva responsabilidade do autor".

2. Vivendo em sua maioria nos Departamentos paraguaios de Alto Paraná, Canindeyu e Amambay. limitrofes com o Brasil, os brasileiros com admissão permanente eram, conforme censo paraguaio de 1990 , 2.144 pessoas. Em 1985, o Ministério das Relaçðes Exteriores do Brasil registrara 37.713 brasileiros residindo legalmente no Paraguai. Desde a década de 70, cálculos de entidades confessionais, ONG's e da imprensa em geral, estimam em 400.000 este número.

3. Sobre a construção da identidade brasiguaios e as caracteristicas étnicas e politicas da organização que elaboraram, ver: SPRANDEL, Marcia Anita Brasiguaios: conflito e identidade em fronteiras internacionais. Dissertação de Mestrado defendida no PPGAS/Museu Nacional - UFRJ, 1992.

4. Sobre as denúncias de violências e prisões, ver Brasil, uma Pátria para os Brasiguaios-Boletim do Movimento pelo Repatriamento dos Brasiguaios. $\mathrm{N}^{\circ}$ 1. Mato Grosso do Sul e $\mathrm{N}^{\circ} 2$, novembro de 1992, Mato Grosso do Sul.

5. Movimento dos Trabalhadores Rurais Sem Terra, Central Única dos Trabalhadores, Secretaria Agrária do Partido dos Trabalhadores, CDDH Marçal de Souza, Comissão Pastoral da Terra, $\mathrm{PCdoB}$, Associação dos Indios Desaldeados Kaguateca, dezenas de sindica- tos profissionais urbanos e ONGs. Também apóiam o MRB a Conferència Nacional dos Bispos do Brasil, através do bispo de Dourados (MS), o Sindicato dos Metalúrgicos de São Bemardo do Campo (SP), o Sindicato dos Químicos e o Sindicato dos Bancários daquele estado.

6. O resultado deste trabalho foi publicado no documento Realidade dos seringueiros brasileiros na Bolivia. Vicariato de Pando, Bolivia; Diocese de Rio Branco (AC), Brasil; CEPAMI, Ji-Paraná (RO), Brasil. Junho de 1991

7. Os estados eram obrigados a repatriar, com o cessar das hostilidades, prisioneiros seriamente doentes ou feridos (arts. 109 e 118 da Convenção de Genebra relativo ao Tratamento de Prisioneiros de Guerra, de 12 de agosto de 1949). "Protected persons" também deveriam ser repatriadas, a não ser que sua partida fosse contrária aos interesses do estado (art. 35 da Convenção de Genebra, relativo a Proteção de Pessoal Civil em Tempo de Guerra).

8. Convenção Relativa ao Status de Refugiados de 28 de julho de 1951 e Protocolo de 1967.

9. A Liga das Naçōes foi criada em Versailles em 1919, e durou até 1939

10. O status de refugiado é usualmente determinado pelas autoridades do país de asilo, com base em entrevistas pessoais, seguidas ou não da emissão de documentos de identidade e viagem. Cabe aos governos dos diversos paises aceitar ou não a autoridade do Alto Comissariado e cooperar ou não com ele.

11. Todas as informaçôes acima foram extraidas da publicação $A$ mandate to protect and assist refugees - 20 years of service in cause of refugees (19511971), publicado pelo UNHCR-Office of the United Nations High Comissiones for Refugees

12. Destaca-se o caso africano. Sobre o problema do repatriamento no contexto das soluçōes contemporàneas duráveis aplicadas para refugiados africanos, as frustrações associadas com os exercicios africanos de repatriamento em termos de obstáculos culturais, econômicos e políticos enfrentados nos processos de repatriamento e na concomitante reabilitação de refugiados em suas áreas de origem, ver ROGGE e AKOL (1989), sobre orepatriamento dos sudanenses do sul, na década de 70 .

13. Sobre a tendência ao acirramento de conflitos interétnicos na região, ver " Xenofobia na América - ódio a estrangeiros invade o Cone Sul", série de reportagens de Solano Nascimento (Prêmio Vladimir Herzog de reportagem 1994) publicada em Zero Hora, de Porto Alegre, de 28 de agosto a $1^{\circ}$ de setembro de 1994.

14. Sobre a perspectiva transnacional dos movimentos de refugiados ver ZOLBERG, SUHRKE e AGUAYO (1986). Os autores estudaram casos de fluxos de refugiados iniciados na Ásia, África e América Latina, desde 1960. Concluiram que fatores internacionais influenciam direta ou indiretamente sobre os conflitos sociais que causam os movimentos de refugiados e tendem a exacerbar seus efeitos. Refugiados seriam produzidos por conflitos que são manifestadamente internacionais, mas que são ligados a conflitos sociais internos entre os antagonistas. Estruturas teóricas para analisar as causas dos movimentos de refugiados precisariam consequentementerefletiro carátertransnacional dos processos envolvidos.

\section{BIBLIOGRAFIA}

\section{- DA MATTA, Roberto}

1994 - "Diplomacia e antropologia" ADB-Boletim da Associação dos Diplomatas Brasileiros. Brasilia, Ano 1. N 6 , outubro. pp. 1-2

\section{- GORDENKER, Leon}

1987-Refugees in International Politics. New York, Columbia University Press.

- HALL, Stuart

1993 - "The local and the global: globalization and ethnicity". In: KING, Anthony (ed.) Culture, globalization and the world system. Macmillam Dpto. of Art and Art History-State University of New York at Binghamton.

- LADAME, Paul Alexis

1958 - Le rôle des migrations dans le monde libre. Paris, Ed. Droz, 525 p.

- MARCUS, Georges

1991 - "Identidades passadas, presentes e emergentes: requisitos para etnografias sobre a modernidade no final do século $\mathrm{XX}$ ao nivel mundial". Revista de Antropologia. São Paulo, USP, No34. pp. 197-221.

- PARRY AND GRANT

1988 - Encyclopaedic dictionary of international law. New York, Oceana Publications.

- PUGLiA, Eliana da Costa e Silva

1993 - "Diário de uma missão consular itinerante" ADB-Boletim da Associação dos Diplomatas Brasileiros. Ano $1, \mathrm{~N}^{\circ} 7$, novembro, pp. 1-2.

- RECONDO, Gregório

1988 - "Comités de frontera: nuevos mecanismos para la integración regional'. Integración Latinoamericana. Ano 12, $\mathrm{N}^{\circ} 132$, marzo. pp. 35-47. - RIBEIRO, Gustavo Lins

1992 - "Bichos-de-obra: fragmentação e reconstrução de identidades". Revista Brasileira de Ciências Sociais. $\mathrm{N}^{\circ} 18$, Ano 7. pp. 30-40.

- ROGGE, John e JOSUHA, Akol

1989 . "Repatriation: its role in resolving Africa's refugee dilemma" , International Migration Review. Vol. XXIII, N², Summer. pp. 184-200.

- UNHCR - Office of the United Nations High Comissioner for Refugees

1971 - A mandate to protect and assist refugees. 20 years of service in cause of refuges (1951-1971). UNHCR

- ZOLBERG, Aristide, SUHRKE, Astri e AGUAYO, Sergio

1986 - "International factors in the formation of refugee movements'. International Migration Review, Vol. $\mathrm{XX}, \mathrm{N}^{\circ} 2$, Summer. pp. 151-169.

\section{NOTÍCIAS DE JORNAL}

- FARIAS, Orlando - "Plano quer repatriar seringueiros'. Jornal do Brasil, 06 de julho de 1994. - LINS DA SILVA, Carlos Eduardo e ROSSI, Clóvis - "FHC quer fim das 'picuinhas' com EUA", Folha de São Paulo, caderno Mais! especial: "A nova geração do Itamaraty é neoliberal ". 18 de dezembro de 1994 p. $5-6$.

- FELICIO, César - "Um fórum bilateral entre governadores". Gazeta Mercantil, 20 de fevereiro de 1995. p.7.

"Refugiados ecológicos são 25 milhōes em todo o mundo". Jornal do Brasil, 30 de março de 1995, p. 9. 